\title{
Tacit versus Overt Collusion Firm Asymmetries and Numbers: What's the Evidence?
}

\author{
by \\ Stephen Davies \\ ESRC Centre for Competition Policy and School of Economics, \\ University of East Anglia \\ \& \\ Matthew Olczak \\ ESRC Centre for Competition Policy and School of Economics, \\ University of East Anglia
}

\section{CCP Working Paper 08-32}

\begin{abstract}
It is conventional wisdom that collusion is more likely the fewer firms there are in a market and the more symmetric they are. This is often theoretically justified in terms of a repeated non-cooperative game. Although that model fits more easily with tacit than overt collusion, the impression sometimes given is that 'one model fits all'. Moreover, the empirical literature offers few stylised facts on the most simple of questions - how few are few and how symmetric is symmetric? This paper attempts to fill this gap while also exploring the interface of tacit and overt collusion, albeit in an indirect way. First, it identifies the empirical model of tacit collusion that the European Commission appears to have employed in coordinated effects merger cases apparently only fairly symmetric duopolies fit the bill. Second, it shows that, intriguingly, the same story emerges from the quite different experimental literature on tacit collusion. This offers a stark contrast with the findings for a sample of prosecuted cartels; on average, these involve six members (often more) and size asymmetries among members are often considerable. The indirect nature of this 'evidence' cautions against definitive conclusions; nevertheless, the contrast offers little comfort for those who believe that the same model does, more or less, fit all.
\end{abstract}

October 2008 
JEL Classification Codes: L13, L41

Keywords: Tacit collusion, collective dominance, coordinated effects, cartels, European mergers, asymmetries, firms numbers

\section{Acknowledgements:}

The research on which this article draws has benefited considerably from helpful comments from many participants in seminars and conferences in Athens, Bonn, Budapest, the OFT, Reading, UEA, Valencia, and Warwick. Malcolm Coate and Morten Hviid have also provided very helpful comments, and Oindrila De has kindly made her data on EC cartels available. We would like to thank, but not implicate, all these people. The support of the Economic and Social Research Council is also gratefully acknowledged. This article is forthcoming in Competition Policy International, Vol. 4, No.2, Autumn 2008.

\section{Contact details:}

Stephen Davies, Centre for Competition Policy, University of East Anglia, Norwich, NR4 7TJ, UK. s.w.davies@uea.ac.uk

Matthew Olczak, Centre for Competition Policy, University of East Anglia, Norwich, NR4 7TJ, UK. m.olczak@uea.ac.uk 


\section{Introduction}

This article explores a strangely under-documented topic in the empirical literature: Are there well-defined (i.e. observable and predictable) differences between the market structures which give rise to tacit collusion as opposed to overt collusion (cartels)?

It is certainly received wisdom that collusion is more likely to occur with fewer leading players in a market and the more symmetric the players are. This was recognised long ago in the traditional Structure-Conduct-Performance paradigm, and was subsequently formalised with the theory of repeated noncooperative games. This wisdom is also shared by practitioners. Dick ${ }^{1}$ explains that case law embraces the presumption that suppliers' ability to coordinate should be closely linked to their fewness in numbers, quoting from FTC vs. PPG Industries: ${ }^{2}$ "[W]here rivals are few, firms will be able to coordinate their behaviour, either by overt collusion or implicit understanding, in order to restrict output and achieve profits above competitive levels." (italics added). He goes on $^{3}$ to provide a persuasive explanation of why asymmetries make collusion difficult.

However, in spite of this consensus, the empirical literature offers few stylised facts on the most simple of questions - how few is few, how symmetric is symmetric, and how, if at all, does this differ between the different forms of collusion? It is true that, for cartels at least, we have extensive case evidence on firm numbers, although less so on asymmetries; but for tacit collusion, remarkably little is known about either. Given that the concept is somewhat elusive and not always easy to tie down in practice, this is hardly surprising.

Unfortunately, if we turn to theory for answers, it is of little assistance. The repeated game is best thought of as a model of tacit collusion, but it is also often assumed to apply equally to cartels, (see added italics above) and there

\footnotetext{
${ }^{1}$ A. R. Dick, Coordinated Interaction: Pre-Merger constraints and Post-Merger Effects, 12(1) GEO. MASON L. REV. 65, 71 (2003) [hereinafter "Dick"]

${ }^{2}$ FTC v. PPG Indus., 798 F.2d 1500, 1503 (D.C. Cir. 1986)

${ }^{3}$ Id. $72-9$
} 
often seems to be an implied presumption that one model fits all. Harrington is surely justified in claiming ${ }^{4}$ that "there is a gap between antitrust practice which distinguishes explicit and tacit collusion - and economic theory - which (generally) does not."

More generally, this nexus of overt and tacit collusion raises a number of policy-relevant questions: "How far are tacit collusion and cartels seen as substitutes?" Do firms only look to form cartels when the legally safer option of tacit collusion is unattainable? Is cartel formation sometimes provoked by a breakdown in tacit collusion? And once a cartel is busted, should we suppose that subsequent behavior will approximate 'competition', or is some sort of tacitly collusive equilibrium a more sensible counterfactual?

For the purpose of this paper, we will define 'market structure' very narrowly by the number of firms in the market and the asymmetries among them. Asymmetries will be defined in terms of market shares - we are concerned with looking for stylised facts applicable across markets - but we should stress that these merely serve as a reduced form indicator of what really matters, i.e. the underlying causes of those asymmetries (see the next section). This is a limitation on our analysis which we freely acknowledge.

Precisely because tacit collusion is difficult to identify and measure in practice, our research strategy is almost inevitably indirect. We begin in section 4 by recounting our recent study of the merger control case decisions by a Competition Authority ("CA"), the European Commission, in which tacit collusion (coordinated effects) appears to have been an issue. We argue that this is probably the only way of assembling a fairly large body of cases, equivalent to existing databases on cartels. Although actual tacit collusion is generally not illegal (hence the absence of actual cases), merger control is one area of policy where CAs are obliged to assess the prospects that tacit collusion may arise. In most major jurisdictions, there is a reasonably large

\footnotetext{
4 J. E. Harrington, Jr., 'The Collusion Chasm: Reducing the Gap Between Antitrust Practice and Industrial Organizational Theory', Slide 7, Csef-Iger Symposium on Economics and Institutions, [hereinafter "Harrington"] available at http://www.econ.jhu.edu/People/Harrington/Capri.ppt
} 
number of such cases, providing the scope for constructing a database sufficiently large to support econometric analysis designed to uncover stylised facts about the sorts of market structures that are associated with tacit collusion - at least as seen through the eyes of the CA. From a European perspective, this is not without interest given the controversies of recent years concerning the Commission's decisions in celebrated cases such as Airtours (1999), ${ }^{5}$ the academic critique of the Nestle-Perrier case ${ }^{6}$ and the 2004 revision to the European Merger Regulation.

Having approached tacit collusion indirectly from this perspective, in section 5 we turn to a sometimes neglected (at least in the mainstream) academic literature: experimental work on tacit collusion. Again, given the obvious difficulties in simulating real world markets in a sterile laboratory environment, empirical experimental research should only be viewed as an indirect source of facts. However, given the difficulties in applying more traditional econometric field analysis, we suggest that experiments, like coordinated effects merger cases, can offer important insights into the subject. In section 6, we move on to more familiar literature on the characteristics of prosecuted cartels. Here, the facts on firm numbers are already reasonably well documented, but we add some new findings on asymmetries which are emerging from our own ongoing research on the structure of a sample of EC cartels.

These three disparate sources offer some thought provoking contrasts: while 'tacit collusion' is typically found in only symmetric duopolies, cartels are usually characterised by more (sometimes far more) than just two players, and often display very pronounced asymmetries in the members' market shares. Section 7 speculates on some of the implications for future research in all three areas: merger analysis, experimental research, and cartels.

The next two sections first provide some preliminaries. Section 2 briefly surveys the standard theoretical expectations on collusion and market

\footnotetext{
${ }^{5}$ M.1424 Airtours/First Choice (1999)

${ }^{6}$ O. Compte, F. Jenny, \& P. Rey, Capacity constraints, mergers and collusion, EuR.Econ REV, 46(1), 129 (2002) [hereinafter "Compte et al."]
} 
structure. Section 3 introduces a simple geometric device, which we employ throughout the article to aid exposition.

\section{Terminology and the Standard Economists' Model of Collusion}

At the outset, we should be clear on terminology. Motta ${ }^{7}$ provides a very clear discussion of the economist's distinction between cartels and tacit collusion, which captures what we take to be the prevailing view - it is certainly ours. While collusion might be defined in economic theory as any market outcome in which prices are high (relative to those in the one-shot non-cooperative equilibrium), collusion should only be considered illegal (i.e. equivalent to a cartel) where firms explicitly coordinate their actions. Where there is no explicit coordination, collusion is tacit and not illegal by default definition. The term 'tacit collusion' is perhaps a little inappropriate - 'tacit coordination' might be less open to misunderstanding - but common practice dictates that we retain 'tacit collusion' here. Of course, in particular cases, there will be debate about certain practices - are they explicit or tacit coordination - but that is not the subject of this paper. ${ }^{8}$

Thus tacit collusion need not, and generally will not, entail explicitly agreed strategies or information exchange, and the spirit of what we have in mind is still captured perfectly by Chamberlin's (oft-quoted, by amongst others, Tirole ${ }^{9}$ ) words of 75 years ago:

\footnotetext{
If each (firm) seeks his maximum profit rationally and intelligently, he will realise that when there are only 2 sellers, his own move has a considerable effect upon his competitors, and that it makes it idle to suppose that they will accept without retaliation the losses he forces upon them. Since the result of a cut by any one is inevitably to decrease his own profit, no one will cut, and although the sellers are entirely independent, the equilibrium result is the same as though there were a monopolistic agreement between them. ${ }^{10}$
}

This anticipates, and fits comfortably with, the contemporary interpretation of

\footnotetext{
${ }^{7}$ M. Motta, Competition Policy: Theory and Practice, Ch. 4, (2004)

${ }^{8}$ For a discussion of this issue, see M. Motta, 'Cartels in the European Union: Economics, Law, Practice', paper written for 'Fifty years of the Treaty: Assessment and Perspectives of Competition Policy in Europe Conference', IESE Business School (2007)

9 J. Tirole, The Theory of Industrial Organization, 240 (1988)

${ }^{10}$ E. H. Chamberlin, The Theory of Monopolistic Competition, 48 (1933)
} 
tacit collusion as a potential equilibrium outcome from a dynamic noncooperative game. That model is routinely recited in all self-respecting industrial organisation textbooks, and is rigorously and concisely summarised by Ivaldi et al. ${ }^{11}$ writing for the European Commission.

Starting from the base case of an homogenous product symmetric duopoly with Nash reversion, Ivaldi et al. derive a series of standard results on the market conditions under which tacit collusion is likely, including: transparent prices, frequent interaction, absence of barriers, and buyer power; but here we are most concerned with firm numbers and asymmetries. They show that the critical threshold for the discount factor increases (and collusion becomes less likely) as the number of firms increases. The intuition is that, with more firms, each firm gets a lower share of the pie from colluding, thus increasing the gains from cheating as well as reducing the attractiveness of long-term collusion. A second factor working in the same direction, but not covered in this model, is that the likelihood that firms are able to tacitly coordinate on a price is reduced the greater the number of firms involved. Turning to market share asymmetries, they show how collusion is most likely with perfect symmetry, but becomes increasingly less likely as the two firms' shares diverge. The intuition here is that a smaller market share reduces the profitability of sticking to the collusive price. However, there is an important caveat on asymmetries - as Ivaldi et al. note, market shares are endogenous, and what really matters are the causes of the asymmetry. For example, if the asymmetry derives from a fundamental asymmetry between the firms in costs, then the high cost (low share) firm has more to gain from undercutting and less to fear from retaliation.

In recent years, the theoretical literature has explored various possibilities on the causes of asymmetry: Rothschild ${ }^{12}$ on costs, Compte et al. ${ }^{13}$ on capacity,

\footnotetext{
${ }^{11}$ M. Ivaldi, P. Rey. P. Seabright \& J. Tirole, 'The Economics of Tacit Collusion' (report for DG Comp, European Commission, 2003) available at http://ec.europa.eu/comm/competition/mergers/studies reports/the economics of tacit collusion en.pdf

${ }^{12}$ R. Rothschild, 'Cartel Stability When Costs are Heterogeneous', INT'L J. INDUS.ORG., 17, 717-734 (1999)
} 
Kühn ${ }^{14}$ on the number of products, and Vasconcelos ${ }^{15}$ on capacity/costs. Although the details of these models vary, the underlying mechanism always works through the asymmetry this causes in the firms' incentives to collude/punish/deviate.

Although the general message that emerges from this literature is that asymmetries reduce the likelihood of collusion, it is clear that any rigorous test of the theory should seek to identify the causes of asymmetry in particular markets. In the current paper, however, because we are more concerned with general stylised facts that might apply across industries, we are almost inevitably reliant on using observed market shares to deduce the degree of asymmetry.

Finally, it should be stressed that models within this genre are presented as models of tacit collusion. However, as hinted earlier, it is not uncommon to use the same model to derive predictions and explanations relating more to cartels. Indeed, it is not difficult to find examples, even in the best textbooks and articles, where the authors appear to use the terms cartels and tacitly collusive groups interchangeably. This might be explained simply by rather sloppy use of language, but one might also argue, along with Martin, ${ }^{16}$ that there is a fundamental disconnect between treating collusion as an outcome of a noncooperative game and the antitrust concept of collusion.

\section{Depicting Market Structure: The Oligopoly Triangle}

The exposition of the remainder of this paper is considerably eased by introducing the following graphical device as a way of summarising and comparing market structures. For a given market in which there are $\mathrm{N}$ firms, this entails plotting the market share of the number one ranked firm against

\footnotetext{
${ }^{13}$ Compte et al. supra note 6

${ }^{14}$ K.-U. Kühn, 'The Co-ordinated Effects of Mergers in Differentiated Products Markets' (University of Michigan, Legal Working Paper Series 34, 2004)

${ }^{15}$ H. Vasconcelos, 'Tacit Collusion Cost Asymmetries and Mergers', 36 (1) RAND J. EcoN. 39-62 (2005)

${ }^{16}$ S. Martin, 'Competition Policy, Collusion and Tacit Collusion', INT'L J. INDUS.ORG, 24, 1299-1301 (2006)
} 
that of the number two ranked firm, as in figure 1. We explain the interpretation of this diagram first where $\mathrm{N} \leq 3$, and then for $\mathrm{N}>3$.

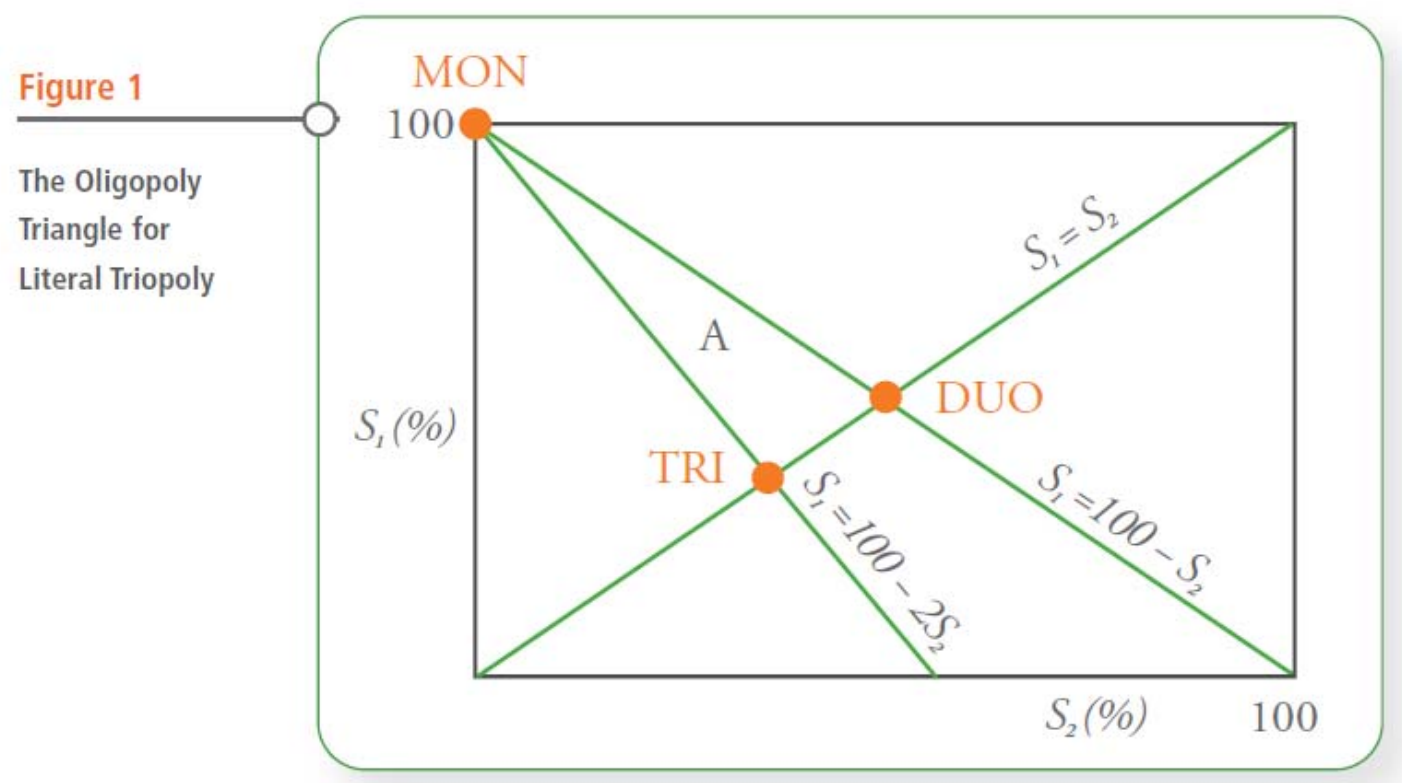

\subsection{Literal Triopoly}

In a market with $\mathrm{N}=3$, with firms ranked by the size of their market shares, $\mathrm{S} 1$, $\mathrm{S} 2$ and $\mathrm{S} 3$, the point $(\mathrm{S} 2, \mathrm{~S} 1)$ must provide a complete characterisation of the structure of that market.

As shown in Box 1, by construction, the point $(S 2, S 1)$ must lie within the $A$ triangle, with the three corners identifying the three limiting market structures: perfect monopoly (MON), symmetric duopoly (DUO), and symmetric triopoly (TRI). Outside these extremes, location within the triangle represents: (i) the level of concentration (if measured by $\mathrm{S} 1+\mathrm{S} 2$, this is higher for points closer to the downward sloping diagonal ( $1=100-S 2)$ ), (ii) the degree of size symmetry between $\mathrm{S} 1$ and $\mathrm{S} 2$ (the distance from the upward sloping diagonal, $\mathrm{S} 1=\mathrm{S} 2$, hereafter referred to as the symmetry diagonal), and (iii) the degree of size asymmetry between S2 and S3 (distance along the symmetry diagonal). 


\section{Box 1 \\ Proof that $\left(\mathrm{S}_{2}, \mathrm{~S}_{1}\right)$ lies in the A triangle, with corners, MON- DUO-TRI}

Given that

(i) firms are ranked by size, $\mathrm{S}_{1} \geq \mathrm{S}_{2}$, and the point must therefore lie on or above the symmetry diagonal, $\mathrm{S}_{1}=\mathrm{S}_{2}$

(i) the sum of shares can not exceed $100 \%$, $\mathrm{S}_{1}+\mathrm{S}_{2} \leq 100$, so the point can not lie outside the downward sloping diagonal, $\mathrm{S}_{1}=100-\mathrm{S}_{2}$

(i) firms are ranked by size, $\mathrm{S}_{2} \geq \mathrm{S} 3$. Thus, by trivial manipulation, $S_{2} \geq 100-S_{1}-S_{2}$, i.e. $S_{1} \geq 100-2 S_{2}$. So the point must lie no lower than the line $S_{1}=100-2 S_{2}$.

\subsection{With More Than Three Firms}

Interpretation of the triangle becomes less clear-cut when there are other firms in the market, but it remains true that the location of any point reveals both the level of two-firm concentration $(\mathrm{S} 1+\mathrm{S} 2)$ and the degree of asymmetry between S1 and S2. Although there is now an indeterminacy on the relative sizes of S3 and all other smaller firms, we can add some further insights by inserting two additional lines to the diagram (figure 2).

Denoting the combined market shares of all other smaller 'fringe' firms by $\mathrm{F}$, then the point will only remain within the original $A$ triangle if $S 2 \geq F+S 3 .{ }^{17}$ Hereafter, we refer to this as the 'literal triopoly' triangle: a sufficient, but not necessary, condition for location within $A$ is that the market is a literal triopoly other structures, with relatively small fringes (in the above sense) will also be located within A.

Second, for all other points lying below $A$, there must be a non-empty fringe $F$ which is reasonably large. In general, as F becomes larger, we will tend to move towards the origin. In fact, we can be a little more precise. As proved in Box 2, all points in the $D$ area close to the origin refer to markets where $F$ is

\footnotetext{
${ }^{17}$ Proof: since $S 1+S 2+S 3+F=100$, then $S 1 \geq 100-S 2$ requires that $100-S 2-S 3-F \geq 100-2 S 2$, i.e. $S 2 \geq F+S 3$
} 
'very large' in the sense that $\mathrm{F} \geq \mathrm{S} 1$; while all points in the $\mathrm{C}$ area refer to markets where F at least exceeds the size of S2. Note, however, that both statements refer to sufficient conditions, meaning that we can not exclude the possibility of F>S1 even in $\mathrm{C}$ or $\mathrm{F}>\mathrm{S} 2$ even in $\mathrm{B}$ - it depends also on the size of $F$ relative to S3. For the same reason, the interpretation of area $B$ is even more indeterminate, although, in general, it is likely that only markets with relatively small $F$ will qualify for inclusion in $B$.
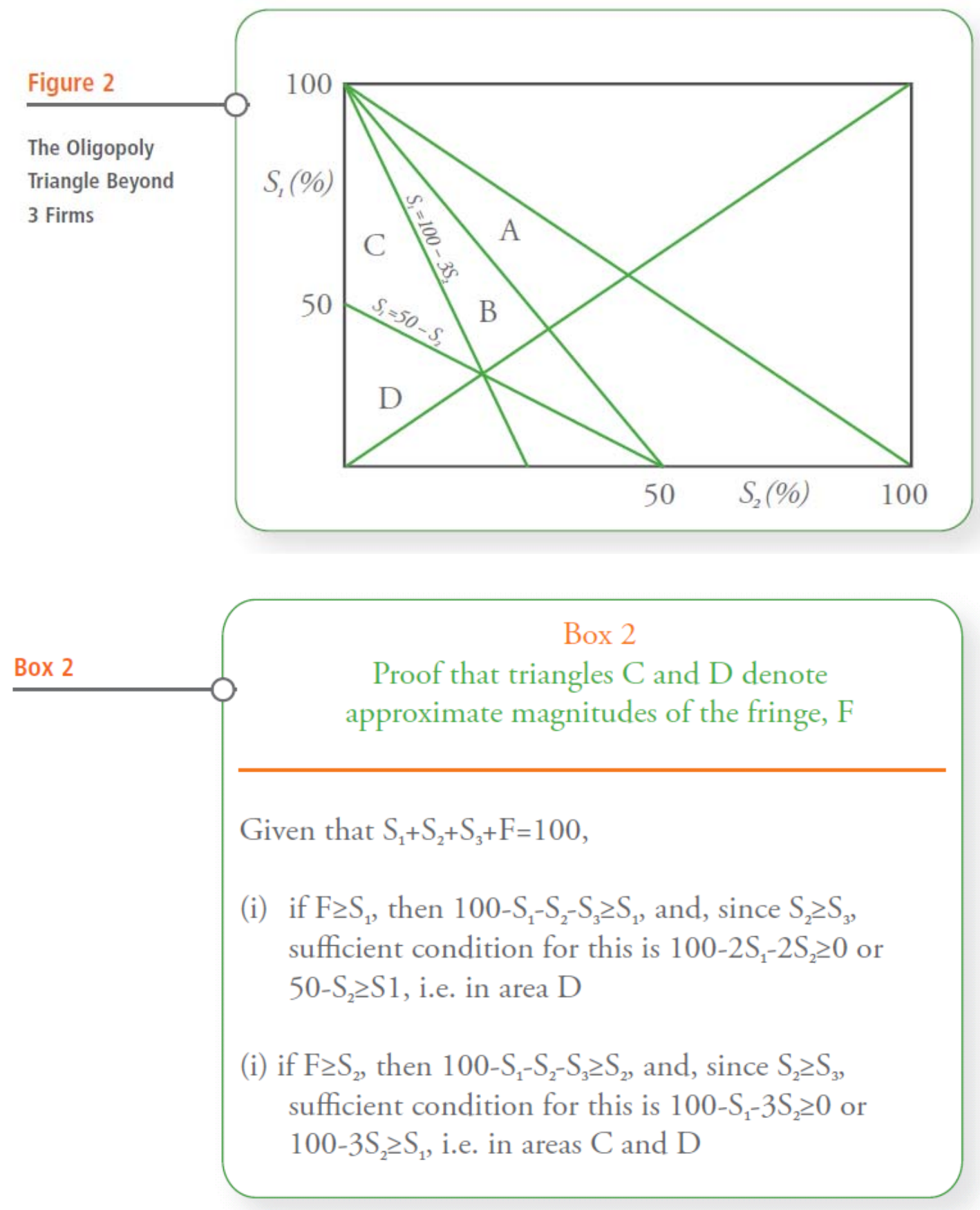

In summary then, we suggest that this 'oligopoly triangle' provides a useful 
first-blush way of summarising and comparing market structures between antitrust cases. The rest of this article puts the triangle through its paces in three applications, each designed to explore the conditions under which collusion might occur. In each case, closeness to the symmetry diagonal will reveal the degree of symmetry between the two largest players and distance from the origin will give a guide to the size of the fringe, with a ranking of the areas $\mathrm{D}>\mathrm{C}>\mathrm{B}>\mathrm{A}$ denoting descending order of the minimum size of $\mathrm{F}$.

\section{An Analysis of Coordinated Effects Mergers as an Indirect Strategy for Observing Tacit Collusion}

As explained in the introduction, the purpose of Davies et al. ${ }^{18}$ was to explore the conditions under which tacit collusion might arise by looking through the eyes of an antitrust authority (in this case the European Commission) in the one area of policy where its decisions reveal its views on tacit collusion, namely those mergers which (may) have coordinated effects (collective dominance). Throughout, we use the terms 'collective dominance' and 'coordinated effects' ${ }^{19}$ synonymously - both refer to mergers where it is anticipated that the firms remaining in the market post-merger (including the merged firm) would be likely to coordinate their actions. Clearly, no CA could ever allege that such coordination would amount to overt collusion - to block a merger on such an interpretation would be tantamount to asserting that firms would act illegally, post-merger! Rather, we take it as given that coordination in this context can only refer to 'tacit collusion'.

At the heart of Davies et al.'s paper is a very simple model of decision making by a CA. It assumes that, when deciding whether a given merger should be allowed to proceed or require remedies or prohibition, the CA considers all markets in which there are overlaps between the merging parties. For each

\footnotetext{
${ }^{18}$ S.W. Davies, M. Olczak \& H. Coles, 'Tacit Collusion, Firm Asymmetries and Numbers: Evidence from EC Merger Cases' (CCP Working Paper 07-7, 2008) [hereinafter "Davies et al., 2008"]

${ }^{19}$ We employ the European terminology, Collective Dominance, merely because our data derive from European cases over the period when this was the European Commission's common parlance for coordinated effects. Since the revision to the merger regulation in 2004, 'coordinated effects' has become common terminology, even within Europe
} 
market, it chooses between nonintervention and declaring a theory of harm, and, if the latter, whether it is single or collective dominance (unilateral or coordinated effects). In coming to its decisions, the CA follows its own merger guidelines $^{20}$ and therefore takes into account: (i) the potential market shares and asymmetries of the leading players post-merger; ${ }^{21}$ and (ii) a checklist of other market conditions, including barriers to entry, buyer power, spare capacity, and transparent prices - these are referred to as the $\mathrm{X}$ conditions. The CA is then assumed to employ a structural model (more precisely, a model of the structure of market shares) to decide between theories of harm, but this only comes into play if the checklist of $X$ conditions is satisfied (e.g. high barriers, no buyer power). Although simple, this model faces a key empirical problem which must be solved if it is to be estimated on a sample of real world mergers. The checklist of market characteristics not only lists the status of near-necessary conditions but these characteristics are also difficult for the researcher to measure, or even proxy, in an objective manner. As explained presently, our solution is to identify the subset of mergers for which the $X$ conditions are likely to be satisfied, and then estimate the structural model only for that subset.

\subsection{The Sample Mergers}

In order to test this model, we assembled a sample of mergers for which there are good reasons to suppose that the Commission seriously contemplated collective dominance as a potential consequence of the merger. (In general, we can assume that single dominance is always contemplated in principle.) We drew from the full population of over 2,400 merger reports published by the Commission, 1990-2004. This is the period from the introduction of the European Merger Regulation (“ECMR”) in $1990^{22}$ up to its revision in 2004. We

\footnotetext{
${ }^{20}$ See http://www.usdoj.gov/atr/public/guidelines/hmg.htm for the US guidelines, and http://eur-lex.europa.eu/LexUriServ/site/en/oj/2004/c 031/c 03120040205en00050018.pdf for the EU guidelines

${ }^{21}$ We follow the convention of all CAs by 'estimating' the hypothetical post-merger market share of the merging firms by simply adding their pre-merger shares

${ }^{22}$ These are all mergers with a European, as opposed to purely national, dimension, and which exceed specified turnover thresholds. See S. W. Davies \& B. R. Lyons, Mergers and Merger Remedies in the EU: Assessing the Consequences for Competition (Edward Elgar, 2007) and S. W. Davies \& M. Olczak, 'Assessing the Efficacy of Structural Merger Remedies: Choosing Between Theories of Harm?'(CCP Working Paper 08-28, 2008) [hereinafter "Davies and Olczak 2008"] for more discussion of the ECMR and remedies
} 
ended the period at 2004 in order to avoid potential complications from any structural break at the time of the revision.

Within the full population, all merger reports were word-searched for the use of one or more of the following phrases: collective dominance, (tacit) collusion, joint dominance, oligopolistic dominance, or coordinated effects. This identified 94 candidate mergers, but closer textual examination revealed that in 32 of these the above phrases were only used in a cursory manner - typically in a throwaway single sentence or short paragraph, revealing that the Commission had easily dismissed the possibility. This leaves 62 mergers in which the text of the Commission's report includes a non-trivial discussion of the possibility that the merger might lead to collective dominance in at least one of the markets involved in the merger. It should be stressed that this search process merely identified all mergers in which collective dominance was seriously considered as a potential problem in at least one market. As will be seen, in by no means all cases did the Commission eventually judge that the merger would lead to collective dominance.

Four key descriptive facts on this sample help set the scene:

1. Collective dominance evidently arises as an issue only very infrequently; in no year during this period does this sample account for more than 4 percent of the total of all mergers. ${ }^{23}$

2. Since we confine our attention to only those cases where there are market overlaps between the merging firms, all mergers were purely horizontal.

3. Nearly all of these mergers are multi-market, involving more than just one product market and, remembering the EU context, more than just one Member State. In total, the 62 mergers covered 456 different markets in which there were overlaps between the merging parties and for which there is useable data. Thus, the average merger covers seven

\footnotetext{
${ }^{23}$ From figures reported by M. Bergman, M. B. Coate, M. Jakobsson, \& S.W. Ulrick in Comparing Merger Policies: The European Union Versus the United States (2007) (working paper on file with the authors), it would appear that coordinated effects is considered far more frequently as an issue by the FTC in the United States. Dick (supra note 1) reports that, between 1999-2003, the FTC successfully challenged 11 proposed mergers under a coordinated effects theory
} 
different markets, but with a skewed distribution around the average. However, in nearly all mergers, the different markets covered are very closely related in product space. This is either because the merger relates to the same product market in different countries and/or even when there is more than one product market, they are closely related. In 54 of the mergers, all markets covered belonged to the same 4-digit industry, and seven involved only two 4-digit industries. (This becomes important below for our assumption of X-homogeneity.)

4. Post-merger, most markets have no more than two or (much less frequently) three major players. As an illustration, defining a 'significant' market share as more than 15 percent, then the sample includes: just one market in which there are five significant players; 12 quadropolies; 89 triopolies; 245 duopolies; and 97 monopolies. Of course, 15 percent is an arbitrary yardstick, but any plausible alternatives yield qualitatively similar conclusions.

\subsection{EC'S Decisions Fitted to the Oligopoly Triangle}

The EC actually intervened in only 25 of these mergers: the merger was prohibited in four cases and allowed to proceed in 21 cases (subject to remedies in one or more markets). We argue that it is only in this sub-sample of mergers - where an intervention occurred in one or more markets - that it is possible to isolate the structural model of single and collective dominance by controlling for other important market characteristics (including barriers to entry, absence of buyer power, and price transparency) that are embodied in the necessary $X$ conditions. This argument relies on an assumption referred to as X-homogeneity; all markets covered by a given merger are assumed to share the same $X$ market characteristics. For example, if the market for large tin cans is characterised by high entry barriers in Germany, the same is likely to be true for small tin cans, as well as for tin cans in France. If this assumption holds, then the decision to intervene in some markets in a particular merger implies that the necessary $X$ conditions have been satisfied - not only for those markets, but also for all other markets covered by the same merger. It then follows that intervention in some markets, but not others, can be explained by structural conditions rather than by $\mathrm{X}$ market characteristics. Of 
course, this can only be an approximation to reality, but Davies et al. ${ }^{24}$ present detailed discussion and empirical evidence in support.

For this reason, we include only these 25 mergers, covering 222 different markets, for an in-depth empirical analysis of the EC's decisions: 29 involved intervention for collective dominance (“CD”), 89 for single dominance (“SD”), ${ }^{25}$ while in the remaining 104 no intervention was deemed necessary. Note then that, in each of these mergers, the Commission reveals that it has considered the possibilities of both SD and CD - typically for different markets in the same merger - and that it is common to find, for a given merger, non-interventions and interventions, as well as different types of interventions across markets.

Figure 3 plots the potential post-merger structures, differentiated by decisions, within the oligopoly triangle. In figure 3(a), for the sake of clarity, the scatters are not shown but represented using head counts of the number of interventions relative to the total number of markets in each of the four areas. The probability of intervention is highest (nearly three-quarters) in the literal triopoly area $A$, and very low in the large-fringe area $D$ (only 8 percent). The intervention rate is now less than one per cent.

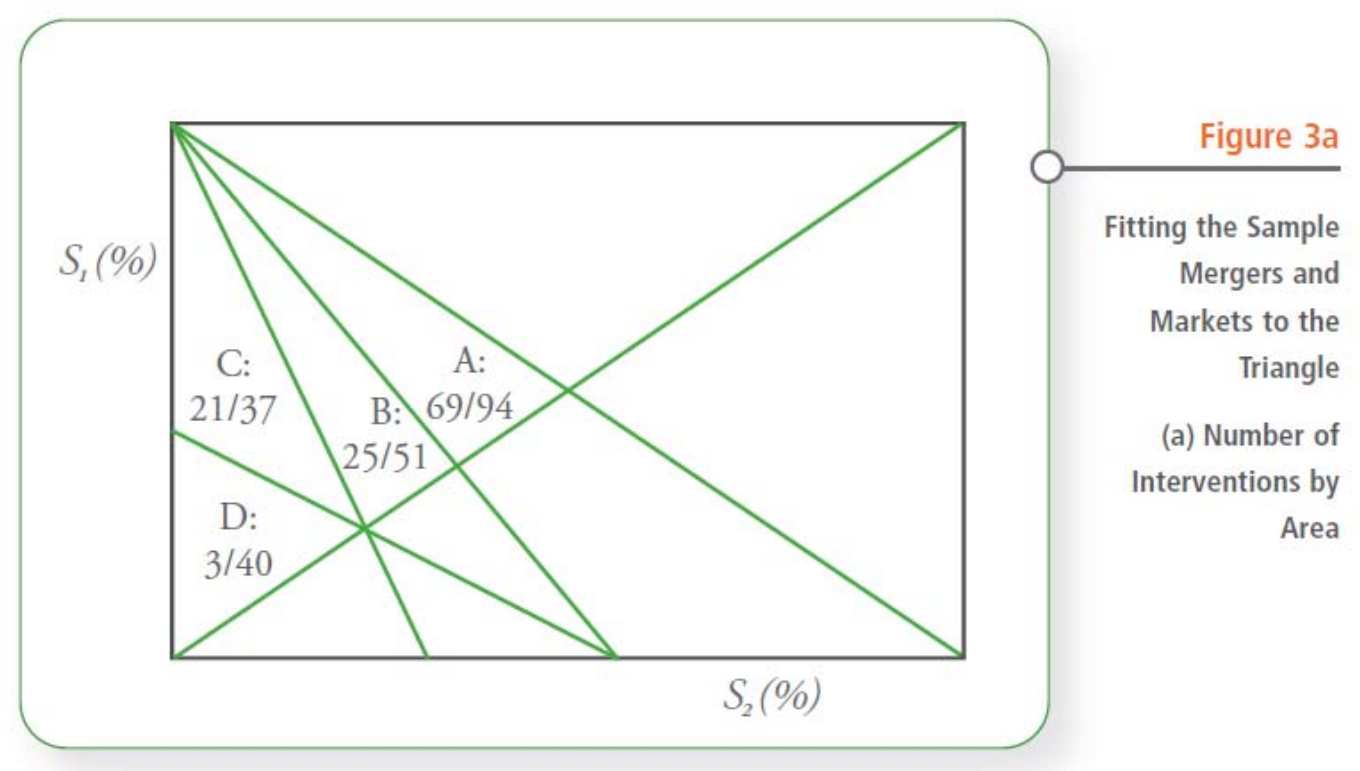

\footnotetext{
${ }^{24}$ Davies et al. 2008, supra note 18 at $36-8$

${ }^{25}$ The collective dominance decisions also include 15 markets in which a group of firms were 'structurally linked' in some way (usually shareholdings). In these cases the EC essentially views these firms as a single entity, and we combine the shares of the linked firms and count them as SD decisions
} 


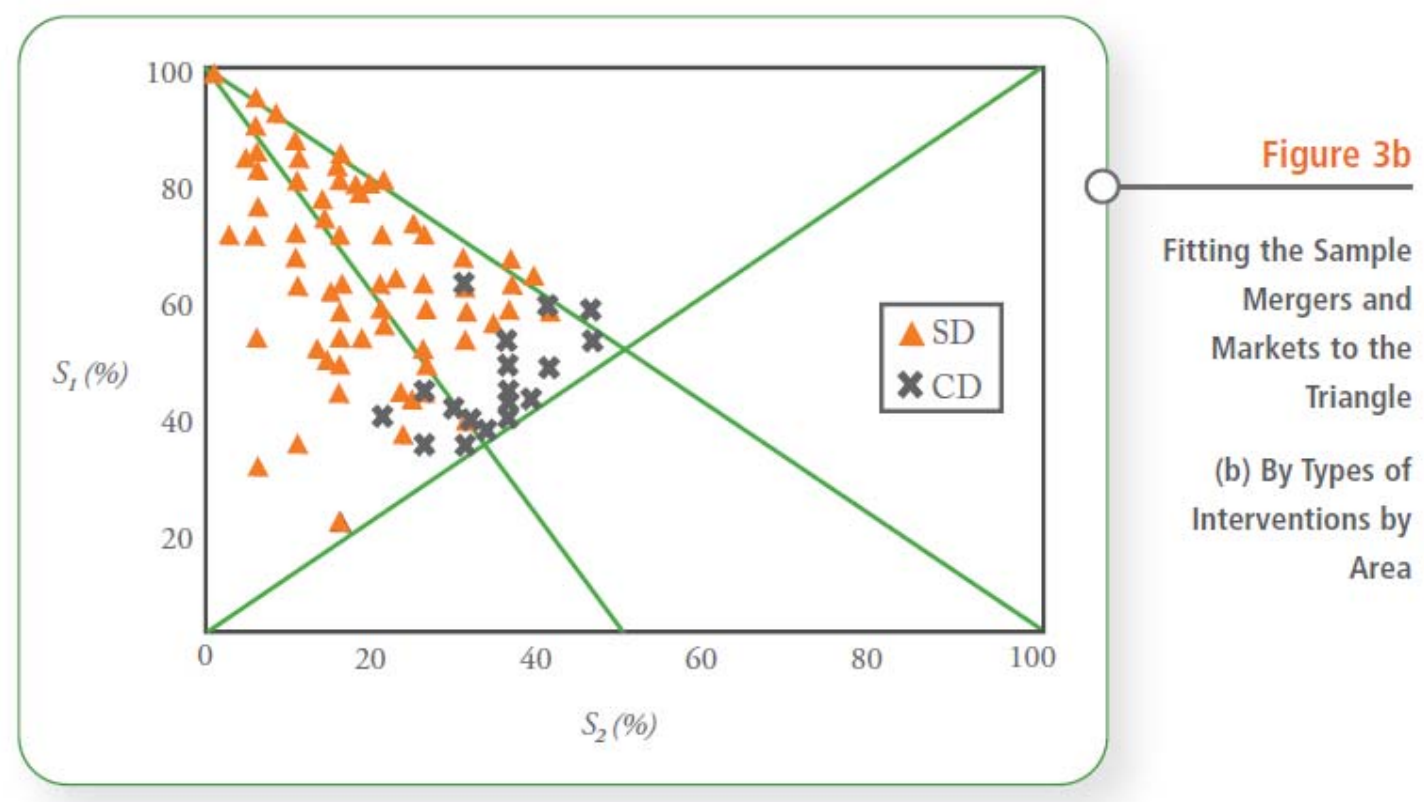

Figure 3(b) shows the full scatter of points, but for the intervention markets only (i.e. now excluding markets without intervention). This clearly demonstrates that $C D$ only occurs within a narrow band just above the symmetry diagonal. It is most common in $A$, and to a lesser extent $B$, but extremely rare otherwise. It appears the European Commission requires, as a necessary condition for collective dominance, that the joint share of the two largest firms be high and that their shares be fairly symmetric. On the other hand, single dominance decisions occur with greater incidence in all areas except D, and typically with pronounced asymmetry between $\mathrm{S} 1$ and $\mathrm{S} 2$, especially in area A.

\subsection{Econometric Model}

In Davies et al., this is formalised using a multinomial logit econometric estimator, in which there are three outcomes (NI, SD, and CD) and there are two simple market share explanatory variables - the sum and ratio of the market shares of the two largest firms: SUM (S1+S2) and RATIO (S2/S1). These two variables are both strongly significant at the 99 percent level in both the equations for SD and CD. They also have the expected signs, indicating that interventions are more likely in concentrated markets (high SUM) and, for CD, in symmetric markets (high RATIO) but for SD in asymmetric markets (low RATIO). The model successfully explains 79 percent of all 222 decisions. 
Figure 4 displays the predicted decisions graphically, and Table 1 shows the different possible outcomes implied, depending upon the size of the number one and two ranked firms.

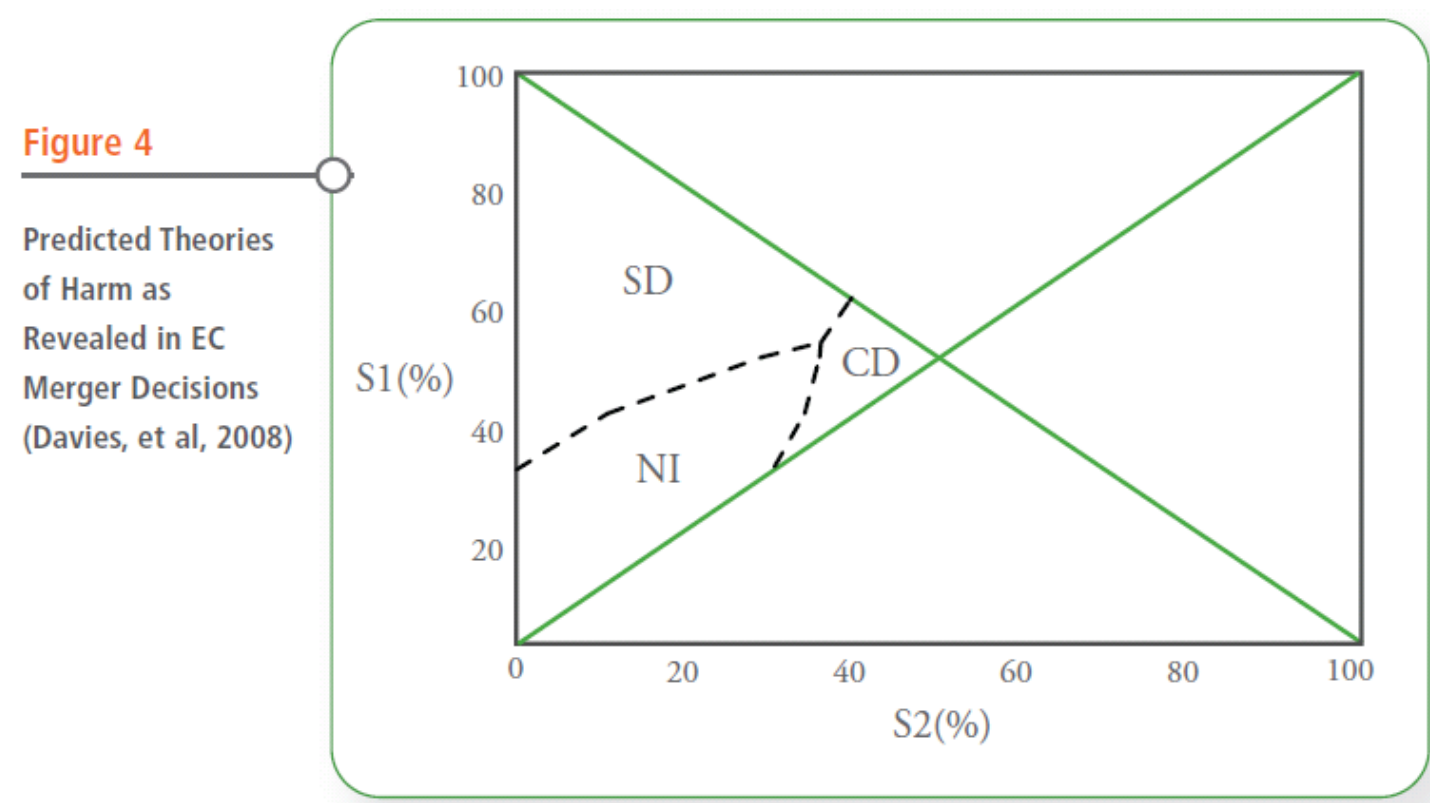

Thus, when the number one ranked firm has a very large post-merger market share (>65 percent), the model predicts that the Commission will always decide SD. However, at lower values for S1, the decision also depends crucially on the size of S2 post-merger. For example, at S1=55 percent, while the Commission will always judge the structure to entail dominance, this will be single dominance if $\mathrm{S} 2$ is relatively small, but collective dominance if S2 is relatively large. Perhaps most interesting is where $\mathrm{S} 1=45$ percent - here all three outcomes can occur, depending on S2: where S2 is 'large', the EC opts for a CD decision, where S2 is 'small', it opts for SD, but for intermediate S2, it opts for NI. This implies that there are some cases where the number two firm is considered to be sufficiently large to counteract the otherwise dominant position of the leader, but not sufficiently large to result in collective dominance (i.e. the resulting size asymmetry rules out tacit collusion).

\begin{tabular}{lccc}
\hline \multicolumn{2}{|c}{$\begin{array}{l}\text { Table } 1 \\
\text { Possible Outcomes at Different Sizes for S1 and S2 } \\
\text { Different outcomes according to size of S2 }\end{array}$} \\
\begin{tabular}{llcl}
$\mathrm{S} 1(\%)$ & NI & $\mathrm{CD}$ & $\mathrm{SD}$ \\
\hline 45 & $18<\mathrm{S} 2<35$ & $35<\mathrm{S} 2$ & $\mathrm{~S} 2<18$ \\
\hline 55 & & $37<\mathrm{S} 2$ & $\mathrm{~S} 2<37$ \\
\hline 65 & & For all S2
\end{tabular}
\end{tabular}


As a short policy postscript, we can report how things have changed beyond the above time period. After the Commission revised its Merger Regulation in May 2004 (up to mid 2007), there were 13 mergers which satisfy our criteria for inclusion in the above sample: non-trivial discussion of coordinated effects (which has now displaced collective dominance as preferred terminology) and a remedy imposed in one or more markets. Strikingly, of the 274 markets covered by these mergers, in only two has the Commission justified an intervention citing the possibility of coordinated effects. ${ }^{26}$ Thus, while the proportion of all mergers matching the criteria for inclusion remains in the region of two percent, indicating an unchanged willingness to contemplate and discuss coordinated effects, the probability that the judgment will actually invoke coordinated markets in any market is now less than one percent.

Moreover, even in these two cases, the decisions are equivocal:

"The Commission does not rule out the possibility that the merger, besides producing non-coordinated effects ... may also lead to a weakening of competitive pressure as a result of coordinated effects" ${ }^{27}$

and

"The [merger] would with high probability lead to non-coordinated effects ... [and] the Commission has serious doubts that [it] may even lead to ... coordinated effects" 28

In other words, not only is the Commission now wary of invoking coordinated effects, but also, rather strangely and in stark contrast to its practice up to 2004 , it couples coordinated effects with unilateral effects. One might interpret this either as a reluctance to come off the fence, or as a belief that both effects might occur simultaneously. The post 2004 period is the subject of our ongoing research. $^{29}$

\section{Experimental Literature}

A cynic, when faced with the above results and asked "How have they

\footnotetext{
${ }^{26}$ In five others, it intervened on the basis of structural links - a not dissimilar proportion to that found pre-2004

${ }^{27}$ Commission Decision, Case COMP/M.3916, T-Mobile Austria/Tele.ring, (Apr. 26, 2006) para 127

${ }^{28}$ Commission Decision, Case COMP/M.4141, Linde/BOC (June 6, 2006), para 179-180

${ }^{29}$ Davies et al. 2008, supra note 18
} 
advanced the understanding of tacit collusion and collusion in general?" might quite justifiably respond: "Nothing, unless one can trust in the ability of a CA to correctly identify such markets." But putting aside disbelief for the sake of the argument, our results on firm numbers and size asymmetries provide some intriguing parallels and contrasts with findings from the adjacent experimental and cartel literatures. We first consider the experimental literature, and here a consensus appears to be emerging.

The generic advantage of experimental as compared to real-world, fieldworkbased econometric, empirical work is that one can control for potentially confounding factors. In the context of mergers, for example, Fonseca and Normann ${ }^{30}$ suggest that "economic conditions, cost gains derived from the merger, barriers to entry or industry maturity" might all obscure any underlying "strategic effects of mergers on pricing behaviour." In the context of tacit collusion, this advantage is arguably even more pronounced given the difficulties in unambiguously identifying tacit collusion in real world settings. For the experimenter, this problem is side-stepped by defining a tacitly collusive outcome as any in which "prices [are] above Nash prices", ${ }^{31}$ where the former are experimentally observed and the latter set by the conditions of the experiment.

To date, experimentalists have devoted far more attention to firm numbers than to asymmetries. Huck et al. conducted a meta analysis on 19 previous studies, 1963-2003, which used Cournot experiments. (See also Engel ${ }^{32}$ for a wider, but more loosely focused meta analysis). These studies involved between two and five symmetric firms and satisfied certain requisites including: no communication among participants, fixed groups interacting repeatedly, homogeneous products, and usually linear demand and costs. Measuring collusion (inversely) by the ratio of the experimental 'industry' output to the analytical Cournot-Nash outcome, they found a statistically significant (at a five

\footnotetext{
${ }^{30}$ M. A. Fonseca \& H. T. Normann, 'Mergers, Asymmetries and Collusion: Experimental Evidence', 118 ECON. J. 387- 400 (2008) [hereinafter "Fonseca"]

${ }^{31}$ S. Huck, H. T. Normann \& J. Oechssler, 'Two Are Few and Four Are Many: Number Effects in Experimental Oligopolies', 53 J. EcoN. BEHAV. \& ORG. 436, fn.4 (2004) [hereinafter "Huck"]

${ }^{32}$ C. Engel, 'How Much Collusion? A Meta-Analysis on Oligopoly Experiments', 3/4 J. COMPETITION L. ECON. 491-549 (2007)
} 
percent level) inverse correlation between firm numbers and collusion. However, on average, it is only in two-firm markets that actual output is less than the Cournot level, leading to their headline finding: "Collusion sometimes occurs in duopolies (but) is very rare in markets with more than two firms." ${ }^{33}$

Huck et al. also conduct some experiments of their own, within a more unified framework than is possible in a meta analysis. These corroborate the meta analysis - collusion sometimes occurs when there are only two firms, but never in markets with four or more. Even in three firm markets, the average outcome is close to the Nash equilibrium. Thus, their message is clearly captured by their title: "Two are few and four are many." ${ }^{34}$ This title is clearly a deliberate implicit reference to Selten's seminal argument that "four are few and six are many." (Although he coined this in a slightly different context, Selten's paper appears to have been a major stimulus to much of the experimental literature.)

The experimental literature on asymmetries is much thinner. Huck et al. report only two in the Cournot setting, the most relevant for current purposes being Mason et al. ${ }^{35}$ In their experiments, outputs were found to be significantly higher (and thus prices lower) where firms have asymmetric, rather than symmetric, costs. Their explanation appeals to the greater difficulties in coordination where firms are dissimilar.

More recently, asymmetries have been explored by Fonseca and Normann ${ }^{36}$ in an experimental setting which closely follows the Bertrand-Edgeworth model employed in Compte et al., ${ }^{37}$ referred to in section 2. Here, firms set prices (as opposed to setting quantity in Cournot) but subject to potential capacity constraints. The range of alternative market structures considered is

\footnotetext{
${ }^{33}$ Huck supra note 31 at 440

34 See R. Selten, 'A Simple Model of Imperfect Competition, Where Four Are Few and Six Are Many', 2 INT'L J. GAME THEORY 141-201 (1973)

${ }^{35}$ C. F. Mason, O. R. Phillips \& C. Nowell, 'Duopoly Behaviour in Asymmetric Markets: An Experimental Evaluation', 74 REV. ECON. \& STAT. 662-670 (1992)

${ }^{36}$ Fonseca supra note 30

${ }^{37}$ Compte et al., supra note 6
} 
admittedly limited, either just two or three firms, and in each case with either symmetric or asymmetric capacities, but this allows for easy interpretation in terms of our oligopoly triangle (figure 5).

\begin{tabular}{|c|c|c|c|c|}
\hline & \multirow[b]{2}{*}{ Structure } & \multicolumn{3}{|c|}{ Firm Capacities } \\
\hline & & $\mathrm{S} 1$ & $\mathrm{~S} 2$ & S3 \\
\hline A & 3 Symmetric & 134 & 134 & 134 \\
\hline B & 2 Asymmetric & 160 & 134 & 108 \\
\hline C & 2 Symmetric & 201 & 201 & \\
\hline D & 2 Asymmetric & 268 & 134 & \\
\hline
\end{tabular}

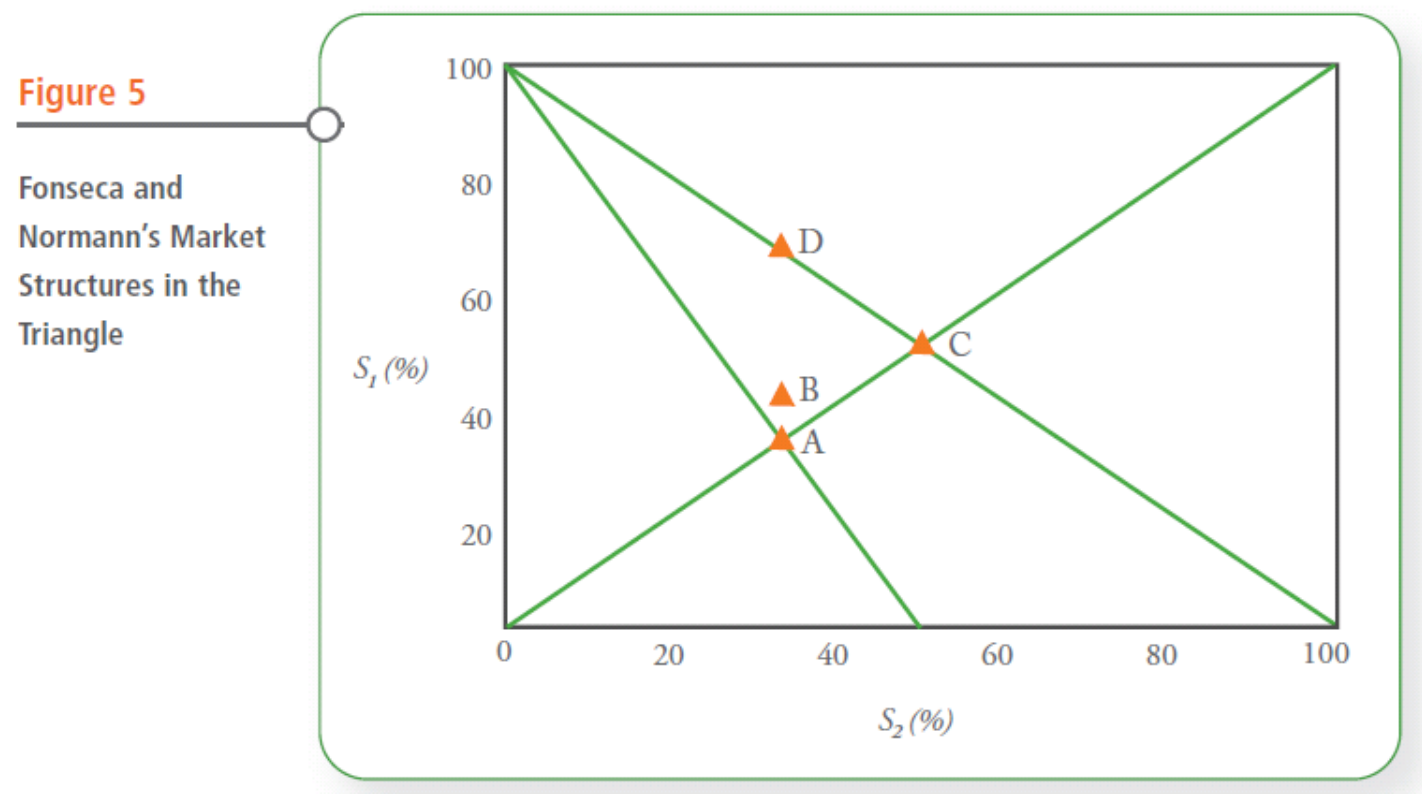

Their experiments are repeated, with fixed groups, over 30 period sessions, thereafter subject to random stopping. In all cases, demand and total capacity are identical. Prices are only compared from period 11 onwards, to allow for learning effects within a repeated game. They report the following ranked weighted mean prices across the four treatments:

$p_{C}>p_{D}>p_{A}>p_{B}$

In other words, price is highest with two equal sized firms (C) and lowest with three unequal sized firms (B). These results are consistent with what we might 
loosely refer to as the 'standard' predictions on the likelihood of collusion.

Thus,

- Reductions in firm numbers lead to increased prices, both in the symmetric and asymmetric cases, i.e. $p_{C}>p_{A}$ and $p_{D}>p_{B}$

- Asymmetry leads to reduced prices, holding numbers constant at either 2 or 3 , i.e. $p_{C}>p_{D}$ and $p_{A}>p_{B}$

As it happens, this ranking is not quite as predicted by the very specific model of Compte et al. ${ }^{38}$ and that should be the subject of future research. But this need not distract us here from the key conclusion for our purposes asymmetry appears to have a definite collusion-dampening role, even where there are just two or three firms.

Of course, as is true for any area of economics, the experimental methodology is not without its limitations. In the current context, it can be argued that it is very difficult to emulate the real world conditions under which tacit collusion can occur with experimental subjects who are often largely inexperienced (in Fonseca and Normann, students from the home university). Thus we should be extremely wary in concluding that tacit collusion in the real world is unlikely with more than two players, and/or with asymmetries. Arguably, real world factors, such as mutual trust and familiarity, fostered over quite long periods of time, are at the heart of tacit collusion. But these factors are very difficult to simulate in a laboratory environment, especially with the fairly trivial prizes given even in the best-funded laboratory. While it is true that the experiments reported above were repeated over many simulated time periods (allowing for learning) with subjects not randomly matched (typically cooperation is never observed experimentally with random matching), a future research agenda must surely include a deeper investigation of communication among

\footnotetext{
${ }^{38}$ In Compte et al., the one shot equilibrium would imply, alternatively, $p_{D}>p_{C}>p_{B}>p_{A}$, because the mixed strategy Nash equilibrium average price is decreasing in the capacity of the smaller firms. This is because, with greater capacity for the smaller firms, the largest firm is more likely to opt for a lower price. On the other hand, in their collusive equilibrium, the critical discount rate increases with the capacity share of the largest firm. If this translates into a lower collusive price, then this predicts:

$p_{A}>p_{B}>p_{C}>p_{D}$. The intuition here is that because the larger is the capacity share of the largest firm, the less severe is the punishment, which makes collusion harder to sustain
} 
participants. ${ }^{39}$ Certainly, we know from other areas of experimental work that the probability of cooperative outcomes increases rapidly as greater communication is allowed (Huck et al. ${ }^{40}$ ). Just how much communication, and of what type, is contentious, but this is at the heart of the antitrust debate about what constitutes proof of overt, as opposed to tacit, collusion.

\section{Cartels}

Unsurprisingly, the empirical literature on cartels is far more extensive than that on tacit collusion since cartel cases are unambiguous and often publicly documented by competition agencies and others. However, caution is needed here, too, because we only observe detected cartels, and sample selection bias can not be ruled out with respect to market structures. Nevertheless, this literature tells a very different story from that of the two previous sections.

First, on firm numbers in general, the evidence may suggest that "cartels are more likely if concentration is large and/or there are relatively few firms in the market/industry" (Grout and Sondregger). ${ }^{41}$ However, exceptions are sufficiently frequent for Levenstein and Suslow ${ }^{42}$ to refer to "the lack of a clear empirical relationship." They offer as possible explanations: sample selection bias (detected cartels may not be a random sample of the population), the potential for a counteracting reverse causality (the softer competition implied by cartels may allow more firms to survive), and, most tellingly for present purposes, the possibility that small numbers markets may be able to tacitly collude as an alternative to cartel formation. A rough indication of the typical number of firms involved in some of the most prominent existing studies of

\footnotetext{
${ }^{39}$ A related experimental literature is already emerging which contemplates the possibility of participants switching from overt to tacit collusion in the face of a leniency program, see for example J. Hinloopen \& A. Soetevent, From Overt to Tacit Collusion: Experimental Evidence on the Adverse Effects of Corporate Leniency Programs (2008) (mimeo available at the University of Amsterdam)

${ }^{40}$ Huck supra note 31 , at 438 Summary 1

${ }^{41}$ P. Grout \& S. Sonderegger, 'Predicting Cartels' (Office of Fair Trading, Economic Discussion Paper OFT773, 15, 2005) [hereinafter "Grout"] available at http://www.oft.gov.uk/shared oft/reports/comp policy/oft773.pdf

${ }^{42}$ M. C. Levenstein \& V. Y. Suslow, 'What Determines Cartel Success?', XLIV J. Econ. LITERATURE 58 (2006)
} 
Second, rather surprisingly, the empirical cartel literature appears to have paid much less systematic attention to asymmetries. However, a casual reading of CA reports on real world cartels suggests that size asymmetries among cartel members can sometimes be quite pronounced. From their sample of 24 EC case studies, Grout and Sondregger ${ }^{44}$ suggest that "we clearly observe a considerable heterogeneity in the market shares held by cartel members," citing four examples in particular: Citric Acid, Methionine, Far Eastern Trade Tariff and Surcharge Agreement (EC), and Ferry Operators-Currency Surcharges.

\begin{tabular}{lccccc|}
\hline \multicolumn{5}{l}{ Table 3 } & \multicolumn{3}{l}{ Number of participants in Cartels } & & \\
Numbers & $\begin{array}{c}\text { Hay \& } \\
\text { Kelley }\end{array}$ & $\begin{array}{c}\text { Fraas \& } \\
\text { Greer }\end{array}$ & Posner & $\begin{array}{c}\text { Levenstein } \\
\text { \& Suslow }\end{array}$ & $\begin{array}{c}\text { De } \\
\text { (EC Cartels) }\end{array}$ \\
\hline Mean & 7.25 & 16.7 & 29.1 & & 6.1 \\
\hline Median & 7 & 8 & 6 to 10 & 8 & 5 \\
\hline Fewer than 10 & $79 \%$ & $60 \%$ & $64 \%$ & $63 \%$ & $85 \%$ \\
\hline
\end{tabular}

Some of our own ongoing work in progress ${ }^{45}$ provides a useful overview on both firm numbers and asymmetries. The database relates to the 41 successfully prosecuted EC cartels, 1990-2006, for which it has been possible to extract the required data on market shares, and excludes all cases involving associations of firms. As can be seen from the last column of Table 3, the median number of firms in this sample was 5 and the mean 6 . Both are slightly lower than the comparable statistics from the previous studies shown in the table, but nevertheless confirm that cartels typically entail larger firm numbers than in either our own work on mergers or in the experimental literature: only eight cartels involved just two firms, three involved three, 22 involved four to seven firms, and 12 involved eight or more firms.

\footnotetext{
${ }^{43}$ Derived from Id., Tables 4 and 5 . De's database is referred to in the text

${ }^{44}$ Grout supra note 41

${ }^{45}$ This is in collaboration with Oindrila De, who has been responsible for the careful reading of the large number of EC case documents necessary to generate the estimates drawn on here
} 
However, our findings on the extent of size asymmetries within this sample are more intriguing. Again, the oligopoly triangle (figures 6) provides a useful quick guide, with the axes, as before, depicting the relative sizes of the two largest players within each cartel. Here, it is important to stress that, for this purpose, we show market shares as percentages of the total size (typically sales) of the cartel. To the extent that cartel members do not account for the entire market, this overstates firms' market shares. In this sample, the median cartel accounts for about 90 percent of the market, but in some cases it is much lower: coverage is less than 70 percent in seven cases. Obviously, if expressed as genuine market shares, a number of the observations would be moved closer to the origin.

For simplicity and comparability with the earlier figure (3a), figure 6(a) first merely reports the counts across the four areas of the diagram. This is in marked contrast with the earlier story of figure 3: less than one third of cartels lie within the 'literal oligopoly' A area, and about a quarter are located in the unconcentrated $C$ and $D$ areas: clearly, explicit collusion can occur within relatively unconcentrated groups of firms.

The contrast is sharpened in figure 6(b) which shows the full scatter, with the fitted curves from our earlier merger analysis superimposed. This focuses more precisely on asymmetries, and it unambiguously establishes that size inequalities are far more pronounced than those found in our earlier coordinated effect mergers. Only five cartels lie within the region of collectively dominant mergers; 11 present structures which would have been judged to be singly dominant had they been the outcome of a merger, and the remaining 25 (i.e. 60 percent) would not have been judged to involve either collective or single dominance. 

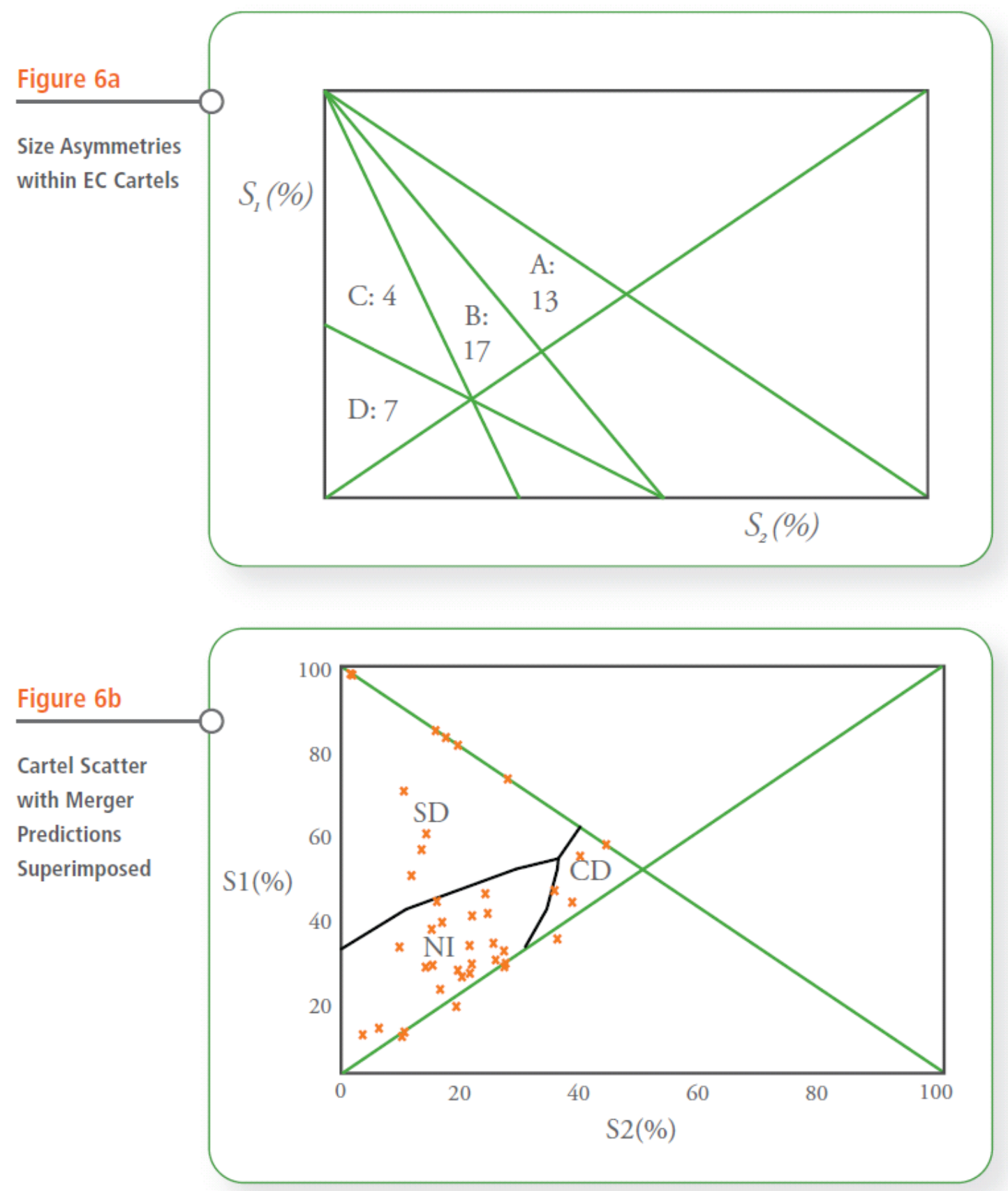

Generally, although it is apparent that a sizeable proportion of cartels do present rough symmetry between S1 and S2 (lying fairly close to the symmetry diagonal), a sizeable proportion do not and this calls into question whether symmetry of market shares is a pervasive feature of real world cartels.

Indeed, it is tempting to speculate from this figure that we can identify three broad types of cartel structure:

- "Tacit-collusive compatible" - in the very limited sense implied by this 
- "Dominant leader" - with the largest firm accounting for roughly 50 percent of the cartels' sales, and its largest rival typically much smaller (say 20 percent or less).

- "Unconcentrated" - with neither of the largest firms accounting for much more than 40 percent or 30 percent, and usually much less. This type is fairly heterogeneous, including five or six cartels which might be categorised as triopoly or quadropoly, but the other 20 entailing very significant fringes.

It would be imprudent to push this typology too far - there is undoubtedly some fuzziness at the edges of the three types, and there are, no doubt, imprecisions in the raw market share data on which it is based. However, we believe the typology provides a very convenient framework within which to draw some of our main implications and conclusions.

\section{Implications and Conclusions}

Our purpose has been to confront our previous findings on the market structural characteristics of coordinated effects EC merger cases, as a proxy for tacit collusion, with what is known from two quite separate empirical literatures - on the one hand, experimental research on tacit collusion, and, on the other hand, the observed market structures of some real world cartels. Underlying this purpose is a desire to assess the empirical similarities between explicit and tacit collusion in the light of a general practice among economists to assume that both phenomena can be understood by what is essentially the same model - the repeated game.

So what have we learned, and what does this suggest for future research? Putting aside some very important caveats for the moment, our results suggest the following: 
- EC coordinated effect merger decisions and our review of the experimental evidence suggests that tacit collusion is rare with more than two firms, and without symmetry.

- EC cartel cases suggest that explicit collusion very often involves more than two firms, a 'typical' number might be five or six, but very often it is much more. Size asymmetries are often quite pronounced within cartels.

This can be developed by drawing on the tentative typology of the previous section as follows. In answer to one of our opening questions, are tacit and overt collusion substitutes? The answer may be yes, but only for a small subset of cartels - the tacit collusive compatible subset that involves just two, roughly equal players. For this subset, a further set of questions follow naturally: why did the firms involved opt for an illegal cartel, when a similar outcome might have been attainable tacitly? Did they emerge historically in the wake of a break-down in a tacit collusion? (This would be consistent with Harrington's ${ }^{46}$ evidence that prices tend to fall prior to the formation of a cartel.) Analogously, once broken, is overt replaced by tacit collusion?

Turning to the dominant firm subset again, was it the dominant firm who was the ringleader? If yes, then why did it choose to instigate a cartel, rather than relying on the cause of its dominance (perhaps a cost advantage or a firstmover advantage) to ensure compliance of its smaller rivals in a nonaggressive tacit understanding? Moreover, are the internal mechanisms employed in this type of cartel distinctively different from those observed in other cartels?

Finally, for the unconcentrated subset, the salient question is: How were these cartels able to form and survive, given that they exhibited neither of the generally expected characteristics of fewness and similarity?

These questions are as real for the academician as they are for the policy

\footnotetext{
${ }^{46}$ Harrington supra note 4 at slide 44
} 
practitioner. Probably the most fundamental distinction between overt and tacit collusion is that meaningful explicit communication is possible in the former but not the latter. From the existence of the unconcentrated subset, it would appear that communication may often considerably extend the feasible boundaries for an aspiring cartel with respect to both fewness and asymmetries, but how is this reconciled with existing theory? The experimental papers we have reviewed above are meticulous in not allowing any communication among participants. Is it possible in future work to relax this restriction in a way that simulates the sort of informal information exchange which, while falling short of hard evidence recognised by the Court, might yet extend the boundary of structures within which tacitly collusive outcomes emerge? Returning to our own work on mergers with coordinated effects, is it simply that the CA (in our case, the European Commission) has been overcautious in employing the coordinated effects theory of harm in its decisions?

We believe that each of the questions posed above merits further research, and therefore endorse Harrington's second sentence below: "...Having drawn this distinction between explicit and tacit collusion, I am
disappointed to say that, due to inadequacies in the underlying theory, the
ensuing analysis will largely ignore it. Nevertheless, it is important to keep this
distinction in the back of our mind and hopefully it'll move to the front of our
collective mind in future research.".47

We hope that the current paper will help nudge the topic closer towards the front of the agenda.

\footnotetext{
${ }^{47}$ J. E. Harrington, Jr., 'Detecting Cartels', in HANDBOOK IN ANTITRUST ECONOMics 4-5 (P. Buccirossi ed., 2008)
} 